\title{
Histopathological examination of concept of left hemiblock
}

\author{
J. C. Demoulin and H. E. Kulbertus
}

From the Department of Morbid Anatomy and the Division of Cardiology, Department of Medical Clinics and Semiology, University of Liège School of Medicine, Liège, Belgium

This paper is concerned with a histological study of the left bundle-branch system in 20 hearts from patients without conduction defects and in Io hearts from patients with left anterior fascicular block.

In addition to the well-known anterior and posterior fasciculi, the left branch was observed to give off a third radiation in II out of the 20 control hearts. This easily identified structure travelled to the midseptal area and emerged either from the common left bundle $(5$ cases) or from the anterior (3 cases) or posterior radiation (3 cases). In the remaining 9 instances, the septal coverage was supplied either by the posterior radiation (3 cases) or by a complicated plexus of ramifications given off by both the anterior and posterior fasciculi (6 cases).

The electrocardiographic pattern of left anterior fascicular block appeared related to severe alterations of the left branch in 9 out of 10 patients. The lesions were predominant on the anterior radiation in 5 cases, but were hardly ever limited to an anterior locus.

It is concluded: (I) that the left-sided Purkinje system appears as constituted of three, rather than two, main peripheral, widely interconnected, networks (anterior, centroseptal, and posterior); and (2) that the pattern of left anterior fascicular block may be considered as a definite sign of left bundle-branch disease, but that no conclusion may be drawn as to the specific location of the histopathological lesions underlying the electrocardiographic abnormality.

In recent years, many papers dealing with the experimental (Rothberger and Winterberg, 1917; Van Bogaert et al., 1958; Uhley and Rivkin, 1964; Watt and Pruitt, 1965, 1969; Watt, Murao, and Pruitt, I965; Rosenbaum, Elizari, and Lazzari, 1968; Medrano et al., 1970) and clinical (Grant, 1956; Davies and Evans, 1960: Corne et al., 1965; Pryor and Blount, 1966; Van Bogaert, 1967; Rosenbaum et al., 1968; Rosenbaum, Elizari, and Lazzari, 1970; Testoni, Narbone, and Tommaselli, 1968; Rosenbaum et al., 1969; Warembourg, Ducloux, and Thery, 1969; Kulbertus, Collignon, and Humblet, 1970a, b; Testoni, Coppotelli, and Tommaselli, 197I) aspects of partial left bundle-branch blocks have appeared. The assumption which forms the basis of the concept of these so-called 'hemiblocks' has been formulated by Rosenbaum and coworkers (1970) who state that: 'The left bundle branch is anatomically a bifascicular system which acts physiologically as such'.

In a recent review of the published reports, Received I5 November 197 I.
Rossi (I97I) pointed out that this subject, though adequately documented on a pathophysiological basis, still needed further investigation from a histopathological viewpoint. Indeed, there is no complete agreement among anatomists as to the modes of subdivision of the left bundle-branch (Rossi, 1971). Moreover, some clinico-histopathological correlative studies have failed to confirm the specific location of the partial lesions of the left bundle-branch underlying the electrocardiographic patterns of hemiblock (Entman, Estes, and Hackel, 1967; Blondeau and Lenègre, 1970).

The present paper reports the results of a morphological investigation of the subdivisions of the left bundle-branch in 20 normal hearts, special attention being paid to the origin of the specific fibres covering the midseptal area. The second part of the article relates the histopathological findings in Io hearts from patients whose electrocardiograms fulfilled the generally agreed criteria for left anterior fascicular block. 


\section{(A) Anatomy of the left bundle-branch system}

Material and methods Histological study of the left bundle-branch system was carried out as follows. A trapezoidal block of left septal myocardium limited on the one side by the junction between the pars membranacea and muscular septum, and on the other side by an imaginary line joining the insertion points of both papillary muscles, was removed and further subdivided into 3 to 6 blocks (Fig. I). The latter were then sectioned serially at $6 \mu \mathrm{m}$ thickness in a plane parallel to the atrioventricular ring. All sections were temporarily retained. Every fortieth section was routinely stained with haematoxylin and eosin and studied. Whenever found necessary by the histological findings of the original sampling, intervening sections were later stained and viewed. The left bundle-branch and its subdivisions were identified by their subendocardial location and by the various differentiating histological features characteristic of the conducting tissue (Lev, Widran, and Erickson, 195I). A drawing of each section was made to represent as closely as possible the location and width of the various subdivisions of the left bundle. A diagrammatic sketch was finally constructed which described the modes of subdivision of the left-sided conducting system.

Twenty hearts from subjects without conduction defects were studied by this method. The patients ranged in age from 22 to 77 years, with an average of 58. There were II men and 9 women.

Results (Fig. 2 and 3) In all cases so far studied, the initial portion of the left branch appeared between the non-coronary and right coronary aortic cusps, as a ribbon-like subendocardial structure running inferiorly and slightly anteriorly with a width varying from 6 to ro $\mathrm{mm}$. The fibres of the left bundlebranch quickly fanned out in the form of fine fasciculi that arranged themselves into two or three main radiations. An anterior radiation was consistently observed to travel in an oblique manner towards the base and medial part of the anterior papillary muscle. This well-defined structure, occasionally bifurcated, was compact, thin, and elongated. The posterior radiation was consistently wider. Appearing as the continuation of the main bundle, it swept smoothly posteriorly towards the base of the posterior papillary muscle and frequently gave off smaller branches running posteriorly. In only two instances (Cases 2 and 14) the posterior radiation was replaced by several separated sub-branches.

Considerable variations among individuals were noted in the distribution of the conduction tissue over the septal area. In II cases, a central, easily identified radiation was observed, which travelled downwards to the

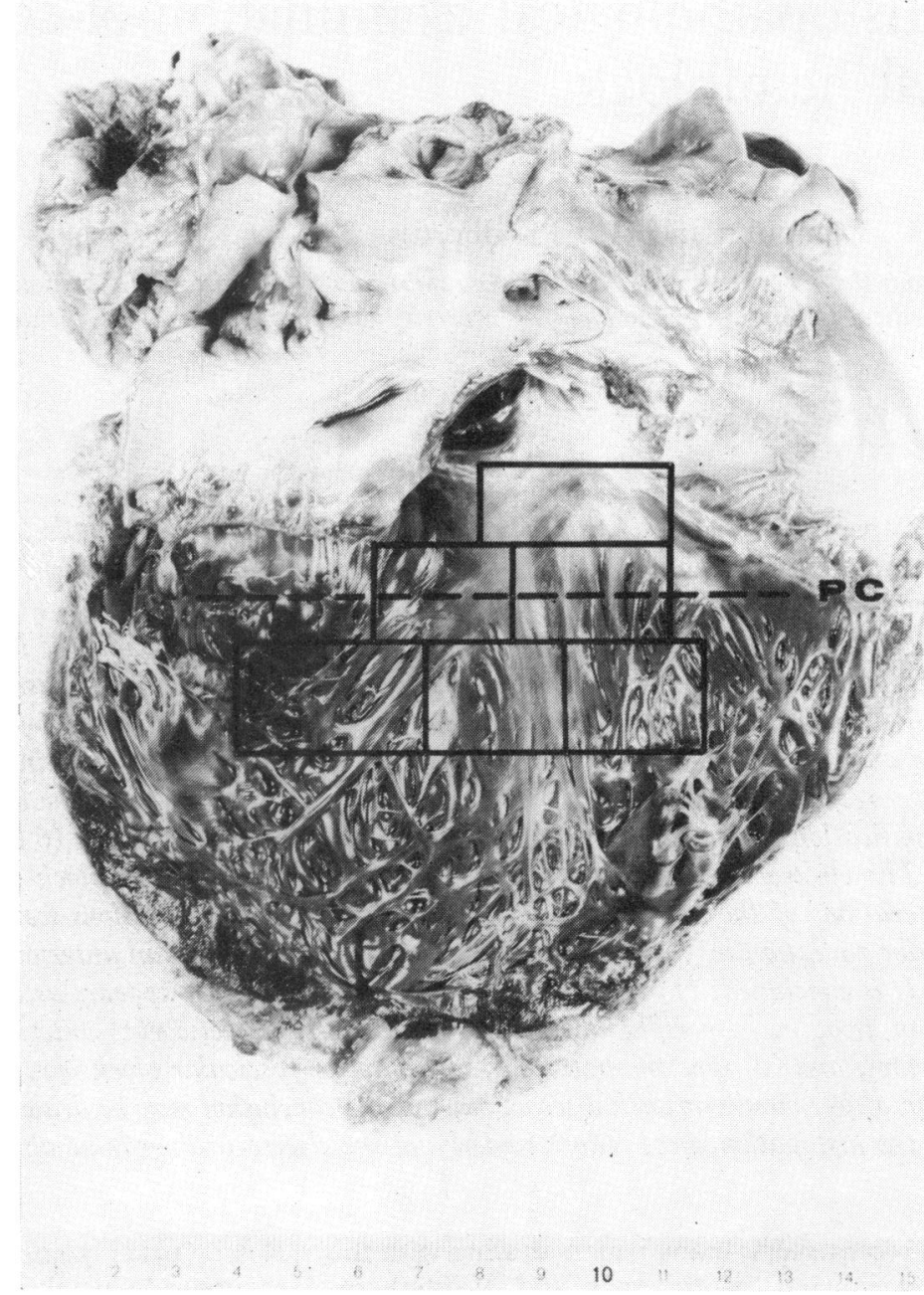

FIG. I Left ventricular cavity. Boxed areas show the portions of the septum that are serially sectioned for the study of the left-sided conduction system. All cuts are made parallel to the AV ring. PC, plane of cutting.

midseptal region. This third radiation, which was sometimes larger than the other two, emerged either from the central portion of the common bundle in the angle formed by the anterior and posterior subdivisions (Cases $I$, $2,3,4$, and 14 ) or from the anterior radiation (Cases 5, 6, and 7) or from the posterior radiation (Cases 8, II, and I2). In 3 cases the septal conducting tissue came from ramifications directly given off by the posterior radiation (Cases 9, 10, and I3). In the 6 remaining instances (Cases 15-20), the septal coverage was supplied by a complicated network of highly interconnected fasciculi emerging from 

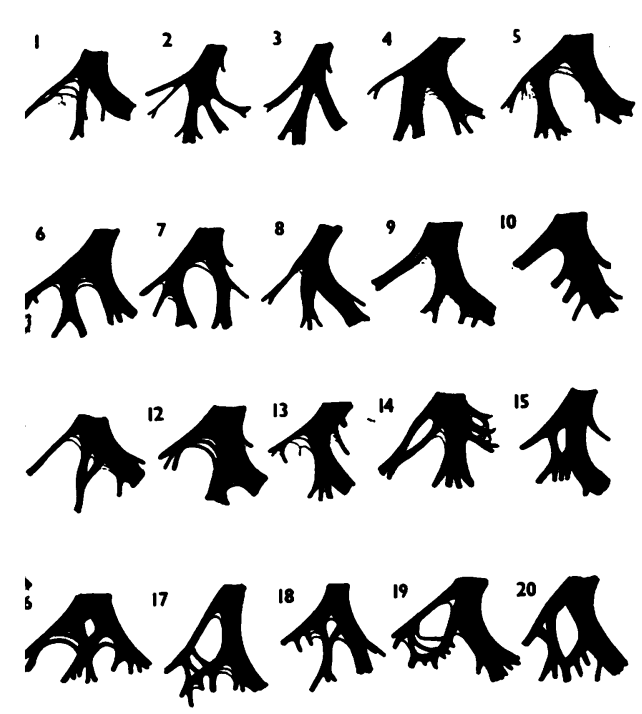

FIG. 2 Diagrammatic sketches of the leftsided conduction system as observed in 20 normal hearts.

both the anterior and posterior radiations. In all cases, the various structures of the left bundle-branch system showed multiple peripheral anastomoses.

$\$$

Comment Since the publication of Rosenbaum et al.'s monograph on intraventricular conduction defects (1968), most cardiologists have agreed that the left bundle-branch might be considered from both the anatomical and physiological viewpoints as a bifascicular system. Nevertheless, in a recent review of the question, Rossi (197I) pointed out that some controversy still persists among anatomists as regards the patterns of subdivision of the left bundle-branch. He quoted, for example, several investigators who stated, in the past and in more recent years, that the left bundle gives off three rather than two main subdivisions (Rothberger and Winterberg, 1917; Doerr, 1957; Schutz, 1958; Robb, 1965; Barry and Patten, 1968). Rossi (197I) assumed that some of the disagreements found in the anatomical description of the left bundle-branch resulted from differences in the techniques of investigation: he particularly insisted upon the shortcomings of the dissection techniques used by Rosenbaum et al. (1968, 1970). As regards the histological method, we personally believe that some difficulties encountered in the studies of the left bundle-branch subdivisions might be accounted for by the angle of cutting chosen for serial sectioning. Cutting in a plane grossly

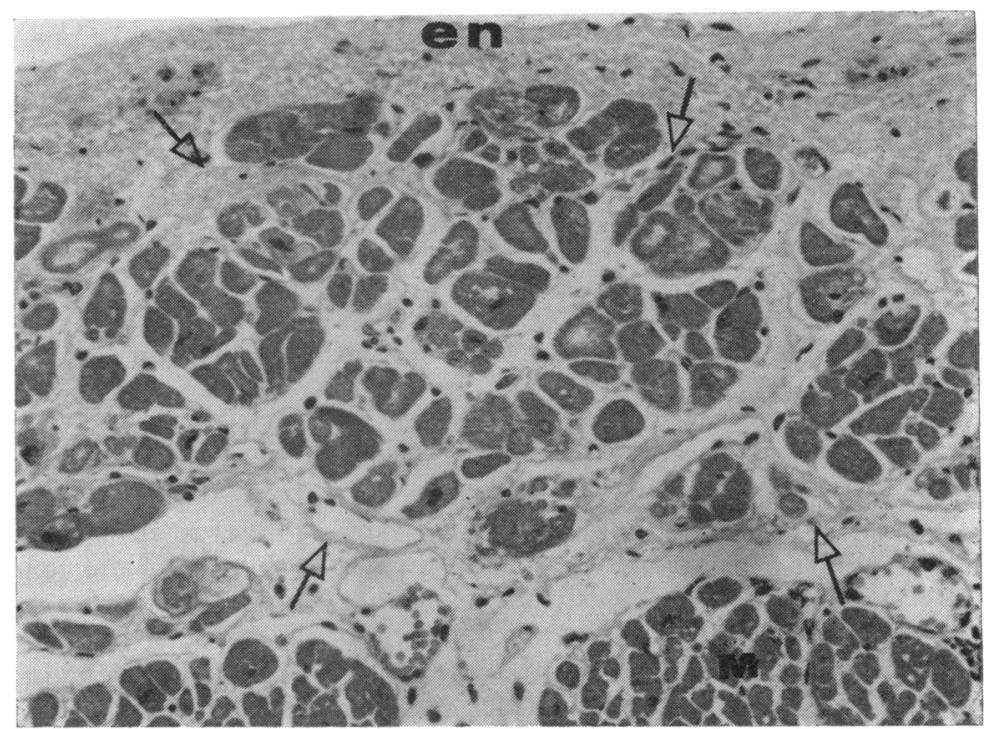

FIG. 3 Initial portion of the anterior radiation of the left bundle-branch from a normal subject, showing numerous large vacuolated conduction fibres. This section is shown to allow comparison with the pathological cases. En, endocardium; $M$, myocardium. ( $H$. and $E$. $\times 164$.

FIG. 4 Case I. Replacement of the left anterior radiation by a thick fibrous strand. Only very few conduction fibres may still be seen. (H. and $E . \times 164$.)

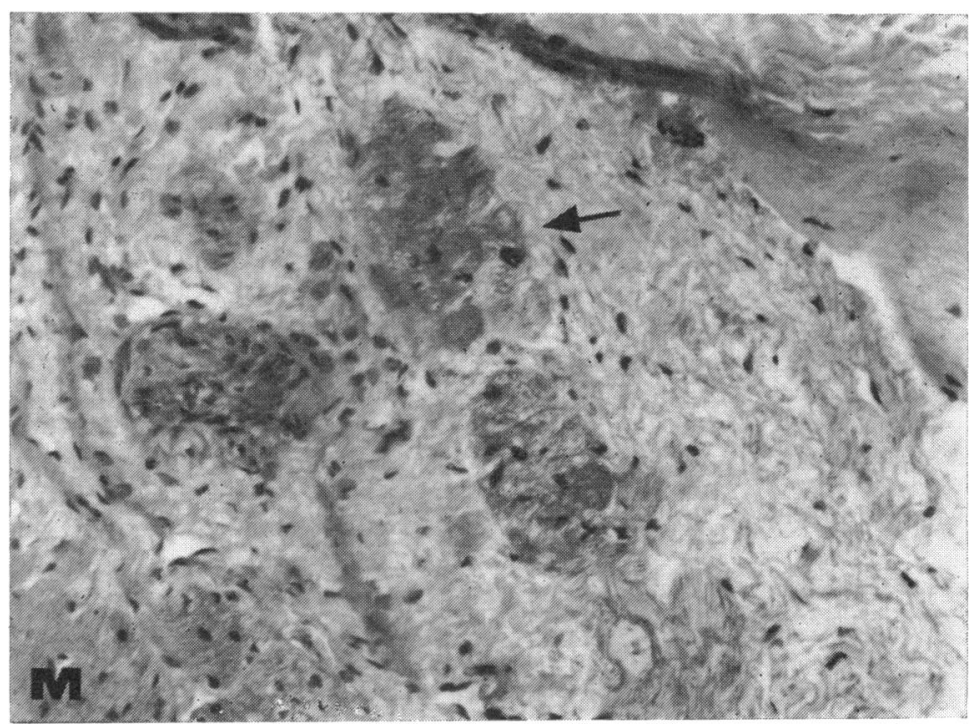


perpendicular to the atrioventricular ring, as is frequently done (Lev et al., 195I ; Lenègre, 1957; Titus, Daugherty, and Edwards, 1963; Rossi, 1969), is not completely satisfactory for the observation of the subdivisions of the left branch since most of these structures are thus cut along their longitudinal axis. We thought that cutting parallel to the atrioventricular ring should yield more easily interpretable data by providing transverse sections of the left branch ramifications.

The data reported herein confirmed the consistent presence of a thin and elongated anterior ramification and of a wider posterior radiation. They disclosed considerable variations among individuals in the distribution of the conducting tissue over the midseptal area. In spite of these variations, the anatomical observations were such that, in most cases, it seemed reasonable to consider the left ventricular Purkinje network as composed of three main, widely interconnected, peripheral parts depending upon the anterior subdivision, the posterior subdivision, and a central subdivision or plexus of ramifications coursing to the midseptal area. Such a description fits in very well with the electrophysiological results recently obtained by Durrer and his group (1970) who found that three endocardial areas of the left ventricle were synchronously excited 0 to $5 \mathrm{msec}$ after the start of left ventricular cavity potential. These three islands of initial excitation may reasonably be assumed to correspond to the termination areas of the three main parts of the left bundle-branch system.

\section{(B) Histopathological features in left anterior fascicular block}

Description of patients Ten hearts from patients with left anterior fascicular block were studied by the same histological method. The electrocardiographic criteria used for recognition of this conduction disturbance were as follows (Kulbertus et al., 1970a). (I) Total QRS duration shorter than 120 msec. (2) Deviation of the mean QRS axis in the frontal plane to the left and superior of $-30^{\circ}$. (3) Ventricular complexes showing a tall $R$ wave in leads $I$ and aVL and a rS morphology in leads II, III, and aVF.

The conduction disturbance was a chronic feature in all of our patients and cases with intermittent or transient left anterior fascicular block were excluded. The series consisted of ro patients, 6 women and 4 men, whose clinical history is summarized in the Table.

Results Data concerning the gross anatomy of the heart and the histopathological examination of the left bundle system in the ro cases with left anterior fascicular block are given in the Table. In one instance, the anterior subdivision was totally interrupted by a thick fibrous strand while the remainder of the left branch appeared devoid of any histological lesion. In 4 cases, scattered alterations were observed to involve the whole left conducting system but the lesions were clearly predominant on the distal portion of the anterior subdivision which showed complete peripheral destruction. In 4 further cases, disseminated degenerative or necrotic changes were seen on the common bundle and peripheral súbdivisions of the left branch. In those 4 patients, the anterior subdivision was neither totally interrupted, nor more severely damaged than the rest of the conducting tissue. In the last case, there were but minor alterations of the left branch which only showed a small island of sclerosis lying in the middle of its posterior radiation.

The observed morphological changes (Fig. 4,5 , and 6) most frequently consisted of fibrosis, fatty infiltration, disruption, and loss of conducting fibres. Sclerotic atrophy was associated with necrotic areas in 2 instances and with severe infiltration by round cells with basophilic cytoplasm in one case. A further observation disclosed general amyloidosis with amyloid deposits destroying the anterior radiation.

In some of the 20 control hearts, especially in those from elderly patients, fine fibrosis throughout the conduction system was observed as well as some loss of fibres at the origin of the left branch. Nevertheless, it was readily apparent that the lesions in the hearts of patients with left anterior fascicular block were incomparably more severe.

Comment Very few articles related to the histopathological lesions underlying the electrocardiographic changes characteristic of left anterior fascicular block have been published. In 1967, Entman et al. studied I5 cases of left anterior parietal block and showed that the extent of anatomical abnormalities varied from severely damaged to histologically normal hearts; no particular region of the myocardium or conduction system seemed more consistently involved than any other. Unfortunately, the criteria used for the selection of cases in this study do not correspond to the currently accepted criteria for left anterior fascicular block and some of the electrocardiographic tracings, shown as illustrations, would undoubtedly not fit with such a diagnosis.

Two abstracts published in 1965 (Hawley and Pryor) and 1967 (Elizari), respectively, reached a different conclusion from the preceding report. Both suggested that the electro- 
TABLE

\begin{tabular}{|c|c|c|c|}
\hline $\begin{array}{l}\text { Case No., sex, } \\
\text { and age at } \\
\text { death }(y r)\end{array}$ & Clinical history & Pathological findings in heart & $\begin{array}{l}\text { Morphological changes in left-sided } \\
\text { conduction system }\end{array}$ \\
\hline
\end{tabular}

death (yr)

I $\quad \mathrm{F} \quad 63 \quad \begin{aligned} & \text { Arterial hypertension; } \\ & \text { angina pectoris; atrial } \\ & \text { fibrillation; cardiac } \\ & \text { failure }\end{aligned}$

$2 \quad M \quad 62$ Arterial hypertension; hypertensive encephalopathy

\section{- 3 F 44 Primary amyloidosis}

Atherosclerosis of aorta and coronary arteries; left ventricular hypertrophy; diffuse myocardial sclerosis

Atherosclerosis of aorta and coronary arteries; biventricular hypertrophy; diffuse myocardial fibrosis; old anteroseptal infarction; multifocal fibrotic scars

Diffuse infiltration of myocardium by amyloid deposits; amyloidosis of arterial walls, more particularly on coronary arterial tree

\section{Atherosclerosis of aorta and coronary arteries; diffuse myocardial fibrosis; left ven- tricular hypertrophy; heavy calcifications of mitral valve}

$5 \quad$ F 77 Angina pectoris; myocarcardial infarction with complete AV block; electrocardiogram recorded before infarction only showed left anterior fascicular block

6 M 49 Congestive cardiomyopathy; heart failure

7 M 60 Old myocardial infarction; recent myocardial infarction

$8 \quad \mathrm{M} \quad 62$ Old myocardial infarction; recent myocardial infarction

9 M 64 Bronchoemphysema; cerebrovascular disease

I0 F 88 Arterial hypertension; congestive heart failure
Severe arteriosclerosis of coronary arteries; left ventricular hypertrophy; thrombosis of anterior descending artery

Diffuse myocardial sclerosis with degeneration of myocardial fibres and interstitial infiltration by polynuclear leucocytes

Scar of postero- and anterobasal infarcts; recent infarc-

Severe atherosclerosis of aorta and coronary arteries; biventricular hypertrophy; scar of postero-basal infarction; recent infarction of lower third of septum; multifocal necrotic areas in septum

Atherosclerosis of aorta and coronary arteries; diffuse fibrosis of myocardium and endocardium; right ventricular hypertrophy

Severe atherosclerosis of aorta and coronary arteries; diffuse myocardial sclerosis; left ventricular hypertrophy tion of lower $\frac{2}{3}$ of septum
Wide subendocardial fibrous strand interrupting anterior radiation and some centroseptal fibres; fine fibrosis on posterior fibres

Diffuse fibrosis of left-sided conduction system; total interruption of anterior radiation

Diffuse amyloidotic alterations of left bundle-branch; interruption of anterior radiation of which only very few fibres remained intact; severe alterations of midseptal fibres; moderate lesions of posterior radiation

Sclerosis and round cell infiltration of left bundle-branch at its origin and on anterior radiation, which was totally destroyed; mild alteration of posterior fibres

Severe subendocardial fibrosis with diffuse involvement of left bundle-branch system; total peripheral fibrotic interruption of anterior radiation

Sclerosis and thickening of endocardium on septal surface; sclerotic atrophy of whole left-sided conducting system

Multiple necrotic lesions throughout left-sided conducting system with subtotal interruption of common left bundle soon after origin

Multiple necrotic areas throughout left-sided conducting system, more particularly in its peripheral subdivisions

Minor alterations of left bundlebranch; small island of sclerotic atrophy in posterior radiation (without interruption)

Widespread fibrosis and fatty infiltration throughout left bundle-branch system 
cardiographic pattern of left anterior hemiblock was related to damage of the anterior division of the left bundle-branch. Confirmatory studies from these laboratories have not yet been reported. Finally, similar disagreements can also be found in papers related to cases with right bundle-branch block and conspicuous left axis deviation (Sugiura et al., 1969; Blondeau and Lenègre, 1970; Rossi, I97I).

In the present series, the histological findings indicated that the electrocardiographic pattern of left anterior fascicular block was related to severe alterations of the left bundlebranch in 9 out ro cases. The anterior subdivision was totally interrupted in 5 instances. The lesions were, however, much more widely distributed than expected from the electrocardiographic terminology: they involved the whole left-sided conduction system in most cases.

\section{Conclusion}

In discussions concerning the pathogenesis of the so-called 'hemiblocks' and 'intraventricular trifascicular blocks', the left bundlebranch is generally considered as an anatomically bifascicular system.

The data obtained in the present study indicate that this description might be somewhat oversimplified. Indeed, in nearly all our cases, a central radiation or, at least, a highly developed plexus of specific fibres was consistently observed over the midseptal area. The left ventricular Purkinje system appeared therefore in most cases to be constituted of three main peripheral networks (anterior, midseptal, and posterior) which are widely interconnected. These anatomical data fit in very well with the electrophysiological results recently obtained by Durrer and coworkers (1970) who found that the excitation of the endocardial surface of the left ventricle simultaneously starts at three widely separated areas which may reasonably be assumed to correspond to the termination zones of the three main parts of the left bundle-branch system.

It is suggested that the problem of left intraventricular conduction disturbances should be reappraised in view of these results. First of all, the validity of the term 'hemiblock', which implies that the bifascicular nature of the left bundle-branch system has been used as the unique basis for terminology, should be questioned. Moreover, the electrocardiographic features attending an interruption of the midseptal fibres should be investi-

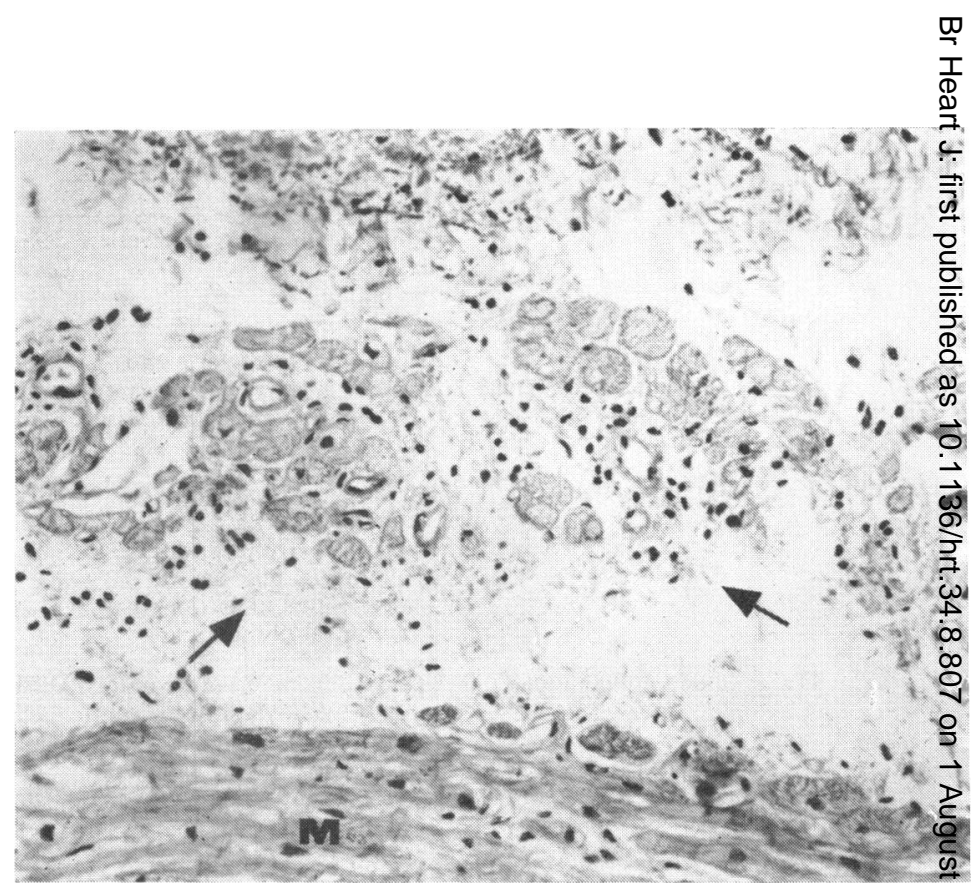

FIG. 5 Case 4. Infiltration of the anterior radiation of the left branch by small round cells. $(H$. and $E . \times 164$.)

FIG. 6 Case 10. Fibrous and fatty infiltration of the left anterior radiation of the left bundle-branch. $(H$. and $E . \times I 64$.

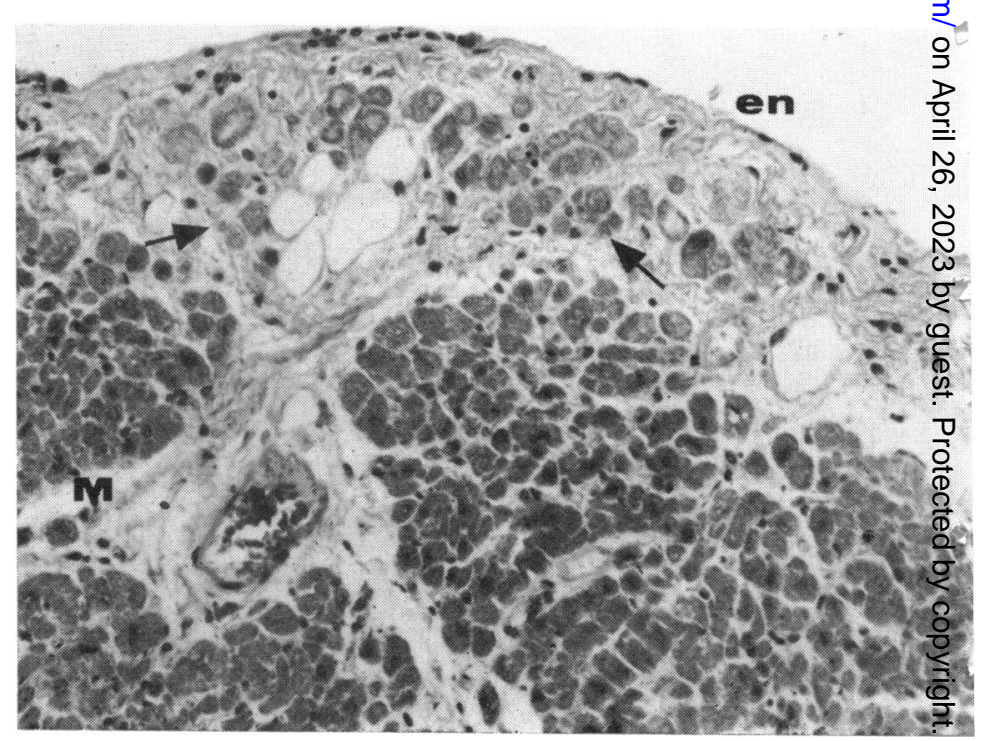


gated. It is possible, for instance, that associated conduction delay along those fibres might account for some of the morphological variants of the vectorcardiographic patterns seen in cases with left anterior fascicular block isolated (Kulbertus et al., 1970a) or combined with right bundle-branch block (Kulbertus et al., 1970b).

The evidence collected from cases with left anterior fascicular block shows that this peculiar electrocardiographic pattern was nearly always related to conspicuous and diffuse alterations of the left bundle-branch system. The lesions involved predominantly the anterior subdivision in approximately onehalf of our cases. Nevertheless, the pathological changes were scarcely ever limited to a left anterior locus, and appeared much more widely distributed than expected from the denomination used in clinical electrocardiography. From a histopathological viewpoint, the electrocardiographic pattern of left anterior fascicular block may therefore be considered as a sign of left bundle-branch disease, but in no way can any definite conclusion be drawn as to the precise topography of the partial bundle-branch lesions.

We would like to thank Professors H. E. Betz and A. Nizet for their most helpful interest and support. We also wish to thank Mr. G. Bourguignon for the illustrations.

\section{References}

Barry, A., and Patten, B. M. (1968). The structure of the adult heart. In Pathology of the Heart and Blood Vessels, 3rd ed., p. 123. Ed. by S. E. Gould. Thomas, Springfield, Illinois.

Blondeau, M., and Lenègre, J. (1970). Bloc Atypique de la Branche Droite. Masson, Paris.

Corne, R. A., Parkin, T. W., Brandenburg, R. O., and Brown, A. L. (1965). Significance of marked left axis deviation. Electrocardiographic-pathologic correlative study. American fournal of Cardiology, $15,605$.

Davies, H., and Evans, W. (1960). The significance of deep $S$ waves in leads II and III. British Heart fournal, 22, 551.

Doerr, W. (1957). Die Morphologie des Reizleitungssystemes, ihre Orthologie und Pathologie. In Rhythmusstörungen des Herzens, p. 19. Ed. by K. Spang. Thieme, Stuttgart.

Durrer, D., van Dam, R. Th., Freud, G. E., Janse, M. J., Meijler, F. L., and Arzbaecher, R. C. (1970). Total excitation of the isolated human heart. Circulation, 4I, 899.

Elizari, M. V. (1967). Estudio histopatologico del sistema de conduccion en cuatro casos de miocarditis cronica chagasica. VII Congreso arg. Cardiol. B. Aires. (Quoted by Rosenbaum et al., 1970.)

Entman, M. L., Estes, E. H., and Hackel, D. B. (1967). The pathologic basis of the electrocardiographic pattern of parietal block. American Heart fournal, 74, 202.
Grant, R. P. (1956). Left axis deviation: an electrocardiographic-pathologic correlation study. Circulation, 14, 233.

Hawley, R. L., and Pryor, R. (1965). Quantitative and electrocardiographic correlation of the conduction system of the heart. (Abstract.) American fournal of Cardiology, 15, 132.

Kulbertus, H., Collignon, P., and Humblet, L. (I970a). Vectorcardiographic study of the QRS loop in patients with left anterior focal block. American Heart fournal, 79, 293.

Kulbertus, H., Collignon, P., and Humblet, I. (I970b). Vectorcardiographic study of QRS loop in patients with left superior axis deviation and right bundle-branch block. British Heart fournal, 32, 386.

Lenègre, J. (1957). Contribution à l'Étude des Blocs de Branche. J. B. Baillière et fils, Paris.

Lev, M., Widran, J., and Erickson, E. E. (195I). A method for the histopathologic study of the atrioventricular node, bundle and branches. Archives of Pathology, 52, 73.

Medrano, G. A., De Micheli, A., Cisneros, F., and Sodi-Pallares, D. (1970). The anterior subdivision block of the left bundle of His. 1 . The ventricular activation process. 2. Experimental vectorcardiographic observations. Fournal of Electrocardiology, 3, 7 .

Pryor, R., and Blount, S. G. (1966). The clinical significance of true left axis deviation. American Heart fournal, 72, 391.

Robb, J. (I965). Comparative Basic Cardiology, p. 392. Grune and Stratton, New York.

Rosenbaum, M. B., Elizari, M. V., and Lazzari, J. O. (1968). Los Hemibloqueos. Ed. Paidos, Buenos Aires.

Rosenbaum, M. B., Elizari, M. V., and Lazzari, J. O. (1970). The Hemiblocks; New Concepts of Intraventricular Conduction Based on Human Anatomical, Physiological and Clinical Studies. Tampa Tracings, Oldsmar, Florida.

Rosenbaum, M. B., Elizari, M. V., Levi, R. J., Nau, G. J., Pisani, N., Lazzari, J. O., and Halpern, M. S. (1969). Five cases of intermittent left anterior hemiblock. American fournal of Cardiology, 24, $I$.

Rossi, L. (1969). Histopathological Features of Cardiac Arrhythmias. Casa editrice Ambrosiana, Milan.

Rossi, L. (197I). Sistema di conduzione trifascicolari ed emiblocchi di branca sinistra. Considerazioni anatomiche ed istopatologiche. Giornale Italiano di Cardiologia, I, 55 .

Rothberger, C. J., and Winterberg, H. (1917). Experimentelle Beiträge zur Kenntnis der Reizleitungsstörungen in den Kammern des Säugertierherzens. Zeitschrift für die gesamte experimentelle Medizin, 5 , 264 .

Schutz, E. (1958). Physiologie des Herzens. Springer, Berlin.

Sugiura, M., Okada, R., Hiraoka, K., and Ohkawa, S. (I969). Histological studies on the conduction system in 14 cases of right bundle branch block associated with left axis deviation. Fapanese Heart fournal, Io, I2I.

Testoni, F., Coppotelli, L., and Tommaselli, A. (I97I). Frequenza, etiopatogenesi e significato clinicoprognostico del blocco focale sinistro anteriore della conduzione intraventricolare. Giornale Italiano di Cardiologia, $\mathbf{1}, 204$.

Testoni, F., Narbone, N. B., and Tommaselli, A. (1968). Aspetti vettocardiografici nei blocchi focali sinistri con elettrocardiogramma di tipo RI-SIISIII. Malattie Cardiovascolari, 9, 379. 
Titus, J. L., Daugherty, G. W., and Edwards, J. E. (1963). Anatomy of the normal human atrioventricular conduction system. American fournal of Anatomy, 113, 407.

Uhley, H. N., and Rivkin, L. M. (1964). Electrocardiographic patterns following interruption of the main and peripheral branches of the canine left bundle of His. American fournal of Cardiology, 13, 41.

Van Bogaert, A. (1967). Valeur clinique de la sinistrodéviation de l'axe électrique dans le plan des dérivations standard. Archives des Maladies du Coeur et des Vaisseaux, 60, 337.

Van Bogaert, A., Van Genabeek, A., Vandael, J., Arnoldy, M., and Van der Henst, H. (1958). Dextrodéviation de QRS dans les dérivations cliniques par lésion ventriculaire gauche. Archives des Maladies du Coeur et des Vaisseaux, 51, 513.

Warembourg, H., Ducloux, G., and Thery, C. (1969). Les troubles de conduction intraventriculaire. Essai de classification. Lille Médical, 14, 400.
Watt, T. B., Jr., Murao, S., and Pruitt, R. D. (1965). Left axis deviation induced experimentally in a primate heart. American Heart fournal, 70, 381.

Watt, T. B., Jr., and Pruitt, R. D. (1965). Electrocardiographic findings associated with experimental arborization block in dogs. American Heart fournal, 69, 642.

Watt, T. B., Jr., and Pruitt, R. D. (I969). Left posterior fascicular block in canine and primate hearts. An electrocardiographic study. Circulation, 40, 677.

Requests for reprints to Dr. Henri E. Kulbertus, Department of Medical Clinics and Semiology, University of Liège School of Medicine, Liège. Belgium. 